\title{
Gli affects the stemness and prognosis of epithelial ovarian cancer via homeobox protein NANOG
}

\author{
HUAN ZHAO ${ }^{1,2}, \mathrm{NA} \mathrm{LI}^{3}$, YICUN PANG ${ }^{1}, \mathrm{JUN}_{\mathrm{ZHAO}}{ }^{1}$ and XIAOHUA WU ${ }^{2,4}$ \\ ${ }^{1}$ Department of Obstetrics and Gynecology, The Third Hospital of Hebei Medical University; \\ ${ }^{2}$ Teaching and Research Section of Obstetrics and Gynecology, Hebei Medical University; \\ ${ }^{3}$ Department of Oncology, Hebei General Hospital; ${ }^{4}$ Department of Obstetrics and Gynecology, \\ The Fourth Hospital of Shijiazhuang, Shijiazhuang, Hebei 050000, P.R. China
}

Received July 18, 2020; Accepted November 10, 2020

DOI: $10.3892 / \mathrm{mmr} .2020 .11767$

\begin{abstract}
Gli proteins are key transcription factors of the Hedgehog $(\mathrm{HH})$ signaling pathway, which is associated with tumorigenesis and drug resistance. However, the role of the HH signaling pathway in epithelial ovarian cancer (EOC) remains unclear. Studies have demonstrated that in some tumors, homeobox protein NANOG (NANOG), a known stem cell marker, is a downstream effector of Gli. However, limited research has been conducted on the association between Gli and NANOG in EOC, particularly regarding their roles in the tumor stemness, such as tumor development, drug resistance and patient prognosis. Thus, the aim of the present study was to explore the aforementioned issues. In this study, Gli1, Gli2 and NANOG expression in EOC tissues was assessed using immunohistochemistry. Gene expression was also assessed using western blotting and reverse transcription-quantitative PCR in SKOV3 cells treated with a Gli inhibitor and an $\mathrm{HH}$ agonist. Furthermore, cell proliferation, colony-forming ability and cisplatin sensitivity were assessed using Cell Counting Kit-8 and colony formation assays. The results showed that both Gli1 and NANOG were associated with cisplatin resistance and EOC disease stage, while the nuclear expression of Gli2 was significantly associated with cisplatin resistance. Together, the expression of Gli and NANOG predicted poor patient prognosis. Targeting Gli with GANT61 impeded tumor proliferation, reversed cisplatin resistance and colony formation, and reduced NANOG expression. To conclude, Gli and NANOG may be effective indicators of platinum resistance and prognosis in EOC. Targeting Gli may reduce the stemness of ovarian cancer cell, which may be achieved via indirect targeting of NANOG.
\end{abstract}

Correspondence to: Dr Xiaohua Wu, Teaching and Research Section of Obstetrics and Gynecology, Hebei Medical University, 361 Zhongshan Road, Shijiazhuang, Hebei 050000, P.R. China E-mail: xiaohuawu1965@sohu.com

Key words: Gli, homeobox protein NANOG, GANT61, ovarian cancer, stemness

\section{Introduction}

Ovarian cancer is a malignant tumor of the female reproductive system characterized by late detection, high risk of drug resistance, and low 5-year survival rate (1). It was previously reported that the mechanisms underlying the morbidity, metastasis, drug resistance and recurrence of ovarian cancer are complex processes involving multiple factors (2). One reason for the poor prognosis of ovarian cancer is the lack of early diagnosis and prognosis markers (2). In addition, the emergence of chemoresistance in ovarian cancer is a major issue that requires unique treatment strategies $(1,2)$.

The Hedgehog $(\mathrm{HH})$ signaling pathway is important for organ and tissue development during embryogenesis (3). It is also involved in various aspects of tumor formation, metastasis, self-renewal and drug resistance in adults (3). Some studies have demonstrated that cancer stem cells are involved in tumor chemoresistance and recurrence, and the $\mathrm{HH}$ signaling pathway was identified as an important pathway associated with cancer stem cells in certain tumors (4-8). Gli is a key transcription factor of the $\mathrm{HH}$ signaling pathway, and its expression is considered to represent the activation of the $\mathrm{HH}$ signaling pathway. In the canonical $\mathrm{HH}$ pathway, in the presence of the sonic $\mathrm{HH}$ ligand, the $\mathrm{HH}$ signaling pathway is activated and Gli expression is increased (9). HH pathway activation occurs not only through canonical HH signaling, but also by ligand-independent $\mathrm{HH}$ signaling, which is known as non-canonical HH signaling (10). In ovarian cancer, the role of the $\mathrm{HH}$ signaling pathway and the function of its key members remains to be elucidated. While some studies have reported that Gli1 is associated with platinum resistance in ovarian cancer $(11,12)$, others suggested that Gli2 has more predictive value (13). Hence, the present study aimed to clarify these controversial findings.

The mechanism underlying the regulation of cancer stem cells by the $\mathrm{HH}$ signaling system is unclear, despite numerous studies on this topic. Homeobox protein NANOG (NANOG) is hypothesized to regulate cell self-renewal and chemotherapy resistance in several tumors and serve as a marker for certain cancer stem cells, such as hepatocellular carcinoma and head and neck tumors (13-16). Additionally, a previous study revealed that in myeloid leukemia tumors, 
NANOG is closely associated with and is a downstream factor of Gli (16). However, little research has investigated the association between Gli and NANOG in ovarian cancer. Therefore, in the present study, clinical ovarian cancer tissue samples and cultured ovarian cancer cells were employed to explore whether the $\mathrm{HH}$ signaling pathway was involved in the tumor development, platinum resistance and prognosis of ovarian cancer and to clarify the relationship between NANOG and Gli.

\section{Materials and methods}

Specimen and clinical data collection. Specimens from 61 cases of epithelial ovarian cancer (EOC) were collected at The Third Hospital of Hebei Medical University (Shijiazhuang, China) between January 2010 and January 2013. All cases were diagnosed as EOC via postoperative pathological examination. The initial surgical procedure involved ovarian cancer staging or cytoreductive surgery, followed by platinum-based combination chemotherapy. Exclusion criteria included the presence of other pathological types of ovarian tumors, tumor recurrence and secondary surgery. The age ranges of the patients was 24-84 years. Tumors were divided into serous adenocarcinoma, mucinous adenocarcinoma and endometrioid carcinoma according to the World Health Organization histological classification system for ovarian tumors (17). Surgical pathological staging and histopathological grading were performed according to the 2009 guidelines of the International Federation of Gynaecology and Obstetrics (18). Among the 61 patients, 17 cases were platinum-resistant (recurred within 6 months of the initial withdrawal of platinum-based chemotherapy) and 44 cases were platinum-sensitive (initial relapse with platinum-based chemotherapy after $\geq 6$ months).

The patients were followed up between July 2010 and July 2019. The follow-up information included age, pathological type, operative-pathological stage, degree of tissue differentiation, lymph node metastasis status, and sensitivity of postoperative platinum-based combination chemotherapy. For deceased patients, the date of death was recorded. The date of the last follow-up was recorded for patients who were lost to follow-up. All patients provided written informed consent prior to inclusion in the study. The ethics committee of The Third Hospital of Hebei Medical University approved the study protocol (approval no. W2020-081-1).

Immunohistochemistry. Tumor tissues were fixed in $10 \%$ formalin for $24 \mathrm{~h}$ at room temperature, embedded in paraffin and serially sectioned (4- $\mu$ m thickness), then dried at $60^{\circ} \mathrm{C}$. The sections were routinely dewaxed in water. Antigen retrieval was performed by heating the section in citrate buffer ( $\mathrm{pH} \mathrm{6.0),} \mathrm{maintaining} \mathrm{it} \mathrm{at} 92-98^{\circ} \mathrm{C}$ for $10 \mathrm{~min}$ and then naturally cooling it to room temperature. The specimens were then rinsed three times in PBS ( $\mathrm{pH} 7.4$ ) for 5 min. Sections were incubated in $3 \%$ hydrogen peroxide solution for $10 \mathrm{~min}$ at room temperature in the dark, then rinsed three times in PBS for $3 \mathrm{~min}$, followed by blocking in 5\% goat serum (Wuhan Servicebio Technology Co., Ltd.) for 10-15 min at room temperature. The sections were incubated with primary antibodies against Gli1 (cat. no. ab151796; 1:500; Abcam), Gli2 (cat. no. 18989-1-AP; 1:500; ProteinTech Group, Inc.) and NANOG (cat. no. ab109250; 1:500; Abcam) at $4^{\circ} \mathrm{C}$ overnight. The sections were washed in PBS and incubated with HRP-conjugated anti-rabbit (cat. no. GB23303; 1:200; Wuhan Servicebio Technology Co., Ltd.) at $37^{\circ} \mathrm{C}$ for $20 \mathrm{~min}$, then rinsed three times in PBS for $5 \mathrm{~min}$. The specimens were incubated in horseradish-labeled streptavidin-avidin working solution at $37^{\circ} \mathrm{C}$ for $20 \mathrm{~min}$ and rinsed three times in PBS for $5 \mathrm{~min}$, followed by the addition of 3 '-diaminobenzidine solution and observation for staining under a microscope for $5 \mathrm{~min}$. The sections were then rinsed under tap water and subjected to hematoxylin counterstaining for $3 \mathrm{~min}$ at room temperature and hydrochloric acid alcohol differentiation. Positive and negative controls were used during the staining process. Human endometrial carcinoma tissue was used as a positive control. For negative controls, the primary antibody was replaced with $\mathrm{PBS}$.

Two double-blinded independent observers evaluated the immunostaining results by light microscope. The stained sections were assessed using the immunoreactive scoring method recommended by Remmele and Stegner (19), with the intensity of staining scored as follows: i) Negative result, 0 points; ii) light yellow staining, 1 point; iii) light brown staining, 2 points; and iv) brown staining, 3 points. The rating range was divided into the following: i) No staining, 0 points in the entire film; ii) $1-10 \%$ staining, 1 point; iii) $10-50 \%$ staining, 2 points; iv) $50-80 \%$ staining, 3 points; and v) $>80 \%$ staining, 4 points. The product of intensity rating and range rating was taken as the total score for analysis, and positivity was defined as a total score $>3$. Positive nuclear staining was defined if $>10 \%$ of cells stained yellow or brown.

Cell culture. SKOV3 cells were donated by the Department of Immunology, Hebei Medical University (Shijiazhuang, China), and seeded at a density of $2-5 \times 10^{5}$ cells $/ \mathrm{ml}$ in RPMI-1640 medium (Gibco; Thermo Fisher Scientific, Inc.) containing $10 \%$ FBS (Zeta-Life, Inc.), penicillin $(100 \mathrm{U} / \mathrm{ml})$ and streptomycin $(100 \mu \mathrm{g} / \mathrm{ml})$, in $5 \%$ carbon dioxide at $37^{\circ} \mathrm{C}$. In the logarithmic growth phase, the cells were digested using $0.25 \%$ trypsin and $0.02 \%$ ethylenediaminetetraacetic acid, and passaged or collected for experiments. Recombinant human sonic HH (SHH) protein (1,000 ng/ml; PeproTech, Inc.) was exogenously added to activate the $\mathrm{HH}$ signaling pathway. Conversely, to inhibit Gli, cells were treated with the Gli antagonist GANT61 (50 $\mu \mathrm{mol} / 1$; Selleck Chemicals).

Reverse transcription-quantitative PCR (RT-qPCR). After treating the cells with SHH and GANT61 for $24 \mathrm{~h}$ according to the protocol described above, RNA was extracted with TRIzol $^{\circledR}$ (cat. no. 15596026; Invitrogen; Thermo Fisher Scientific, Inc.), and the concentration and purity were determined via spectrophotometry. The PrimeScript RT Reagent Kit with gDNA Eraser (Takara Bio, Inc.) was used for RT to cDNA, according to the manufacturer's instructions, and the amplification system was configured according to the Takara TB Green Premix Ex Taq II (Takara Bio, Inc.). Thermocycling conditions were as follows: $95^{\circ} \mathrm{C}$ for $30 \mathrm{sec}$, then $95^{\circ} \mathrm{C}$ for $30 \mathrm{sec}$ and $60-62^{\circ} \mathrm{C}$ for $30 \mathrm{sec}$ for 40 cycles. The following primer pairs were used for qPCR: Gli1 forward, 5'-TGGAGA AGCCGAGCCGAGTATC-3' and reverse, 5'-TGGAGCAGG ACGGTCAGCAG-3'; Gli2 forward, 5'-CCTGCACGTCAG 
AGCCATCAAG-3' and reverse, 5'-TCTCCACGCCACTGT CATTGTTG-3'; NANOG forward, 5'-GCCTCCAGCAGA TGCAAGAACTC-3' and reverse, 5'-CCAGGTCTGGTTGCT CCACATTG-3'; p-glycoprotein (MDR1) forward, 5'-GAT TGCTCACCGCCTGTCCAC-3' and reverse, 5'-CGTGCC ATGCTCCTTGACTCTG-3'; and GADPH forward, 5'-CAG GAGGCATTGCTGATGAT-3' and reverse, 5'-GAAGGCTGG GGCTCATTT-3'. GAPDH was used as a reference gene. Gene expression was assessed using the $2^{-\Delta \Delta C q}$ method (20).

Western blotting. Total protein extraction was performed using RIPA buffer (cat. no. 89900; Thermo Fisher Scientific, Inc.), protein concentration was detected using a BCA protein assay kit (cat. no. 23225; Pierce; Thermo Fisher Scientific, Inc.), and $50 \mu \mathrm{g}$ protein was loaded on a $10 \%$ polyacrylamide gel and separated. Separated proteins were then transferred to nitrocellulose membranes (cat. no. IPVH00010; EMD Millipore), and membranes were blocked with $5 \%$ skimmed milk at room temperature for $1 \mathrm{~h}$. Then, membranes were incubated with the following primary antibodies for $12-16 \mathrm{~h}$ at $4^{\circ} \mathrm{C}$ : Rabbit polyclonal anti-GLI1 (cat. no. ab151796; 1:1,000; Abcam), rabbit polyclonal anti-GLI2 (cat. no. 18989-1-AP; 1:1,000; ProteinTech Group, Inc.), rabbit polyclonal anti-NANOG (cat. no. ab109250; 1:1,000; Abcam), anti-MDR1 (cat. no. BS-1468R; 1:2,000; BIOSS) and mouse monoclonal anti- $\beta$ actin (cat. no. GB12001; 1:3,000; Wuhan Servicebio Technology Co., Ltd.). Following which, membranes were incubated for $30 \mathrm{~min}$ at $37^{\circ} \mathrm{C}$ with HRP-conjugated anti-rabbit (cat. no. GB23303; 1:3,000; Wuhan Servicebio Technology Co., Ltd.) and anti-mouse (cat. no. GB23301; 1:3,000; Wuhan Servicebio Technology Co., Ltd.) secondary antibodies. Images of the immunoblot bands were captured on X-ray film (Kodak) and then scanned with an Epson scanner (Epson V300 Photo; Epson America, Inc.). Bands were semi-quantified by densitometric analysis using AlphaEaseFC ${ }^{\text {TM }}$ software version 4.0 (Genetic Technologies, Inc.).

Proliferation assay. A single-cell suspension of SKOV3 cells was adjusted to a density of $2-5 \times 10^{4}$ cells $/ \mathrm{ml}$, plated into a 96-well plate (100 $\mu 1 /$ well, 3 replicate wells per condition) and the plates were incubated for $24 \mathrm{~h}$. Different groups were classified according to the following treatments to activate the HH signaling pathway or inhibit Gli: i) SHH at concentrations of 500, 1,000 and $1,500 \mathrm{ng} / \mathrm{ml}$; ii) GANT61 at concentrations of 20,50 and $100 \mu \mathrm{mol} / 1$; iii) the negative control group without any treatment; and iv) the blank control in the form of cell-free medium. After 24, 48 or $72 \mathrm{~h}$ of drug treatment, $10 \mu \mathrm{l}$ Cell Counting Kit-8 (CCK-8) solution (Zeta-Life, Inc.) was added to each well. The specimens were then cultured at $37^{\circ} \mathrm{C}$ for $4 \mathrm{~h}$, and the absorbance at a wavelength of $450 \mathrm{~nm}$ was measured.

Determination of the $I_{50}$ of cisplatin in SKOV3 cells. Cells were plated as described for the proliferation assay. The drug concentrations were selected according to the results of the proliferation assay and treatment groups were prepared as follows: i) $1,000 \mathrm{ng} / \mathrm{ml} \mathrm{SHH}$ for $24 \mathrm{~h}$; ii) $50 \mu \mathrm{mol} / 1$ GANT61 for $24 \mathrm{~h}$; and iii) a negative control group without any treatment. After $24 \mathrm{~h}$, each treatment group was divided into six subgroups, and cisplatin was added at concentrations of $0.1,0.2,0.4,0.8,1.5,2.0,3.0$ and $4.0 \mu \mathrm{g} / \mathrm{ml}$. The five concentrations in each group were chosen based on the concentration range that resulted in different survival rates. After 24, 48 or $72 \mathrm{~h}, 10 \mu \mathrm{l}$ CCK- 8 solution was added to each well and the absorbance at a wavelength of $450 \mathrm{~nm}$ was measured, after culturing at $37^{\circ} \mathrm{C}$ for $4 \mathrm{~h}$. The cell inhibition rate was calculated, and the $\mathrm{IC}_{50}$ of different cisplatin concentrations on cells was determined via Probit Analysis using SPSS version 17.0 (IBM Corp.).

Colony formation assay. SKOV3 cells $\left(2-5 \times 10^{5}\right.$ cells $\left./ \mathrm{ml}\right)$ were prepared as a single-cell suspension and seeded into a six-well plate. Once the cells were attached, the following treatments were added: i) $1,000 \mathrm{ng} / \mathrm{ml} \mathrm{SHH}$ for $24 \mathrm{~h}$; ii) $50 \mu \mathrm{mol} / 1$ GANT61 for $24 \mathrm{~h}$; and iii) no treatment in the negative control group. After $24 \mathrm{~h}$ of culture, they were digested into individual cells and re-suspended in RPMI-1640 medium containing $10 \%$ fetal calf serum (Zeta-Life, Inc.). The cells were seeded into a six-well plate at $1 \times 10^{3}$ cells/well and gently rotated to disperse the cells uniformly. The cells were incubated for $1-2$ weeks at $37^{\circ} \mathrm{C}, 5 \%$ carbon dioxide and saturated humidity. The solution was changed every 2 days and cell growth was observed. After 2 weeks, the cells were harvested for observation of colony formation. The cells were fixed with formaldehyde for $30 \mathrm{~min}$ at room temperature, then stained with $10 \%$ Giemsa stain for $15 \mathrm{~min}$ at room temperature. The staining solution was then washed away slowly with running water and cells were air-dried, observed with a light microscope (magnification, x200) and photographed. A colony was defined as $>50$ cells.

Statistical analysis. Experimental data were analyzed using SPSS version 17.0 (SPSS, Inc.). Correlation analysis was performed using Spearman's correlation coefficient. Quantitative results are expressed as the mean $\pm \mathrm{SD}$, and differences between groups were assessed using ANOVA followed by Tukey's post hoc test. The association between protein expression and the clinical-pathological diagnosis of EOC was assessed using the $\chi^{2}$ or Fisher's exact test (for contingency tables that contain cells with $<6$ individuals). Survival rates were analyzed using Probit Analysis. Survival curves were plotted and compared using the Kaplan-Meier method with a log-rank test, and multi-factorial analysis was performed using Cox regression in SSPS. $\mathrm{P}<0.05$ was considered to indicate a statistically significant difference.

\section{Results}

Expression of molecules in EOC and association with clinicopathological features. Gli1 and Gli2 expression in 61 cases of EOC were detected by immunohistochemistry (Fig. 1). The results showed that Gli1 was mainly expressed in the cytoplasm, and there were 38 cases positive for cytoplasmic Gli1 (62.3\%). There were no significant associations between Gli1 expression and patient age, lymph node metastasis, pathological tissue type and histopathological grade $(\mathrm{P}>0.05)$. The cytoplasmic expression of Gli1 was significantly higher among patients with platinum-resistant disease $(\mathrm{P}=0.009)$ and was associated with the pathological surgical stage of the patients. 

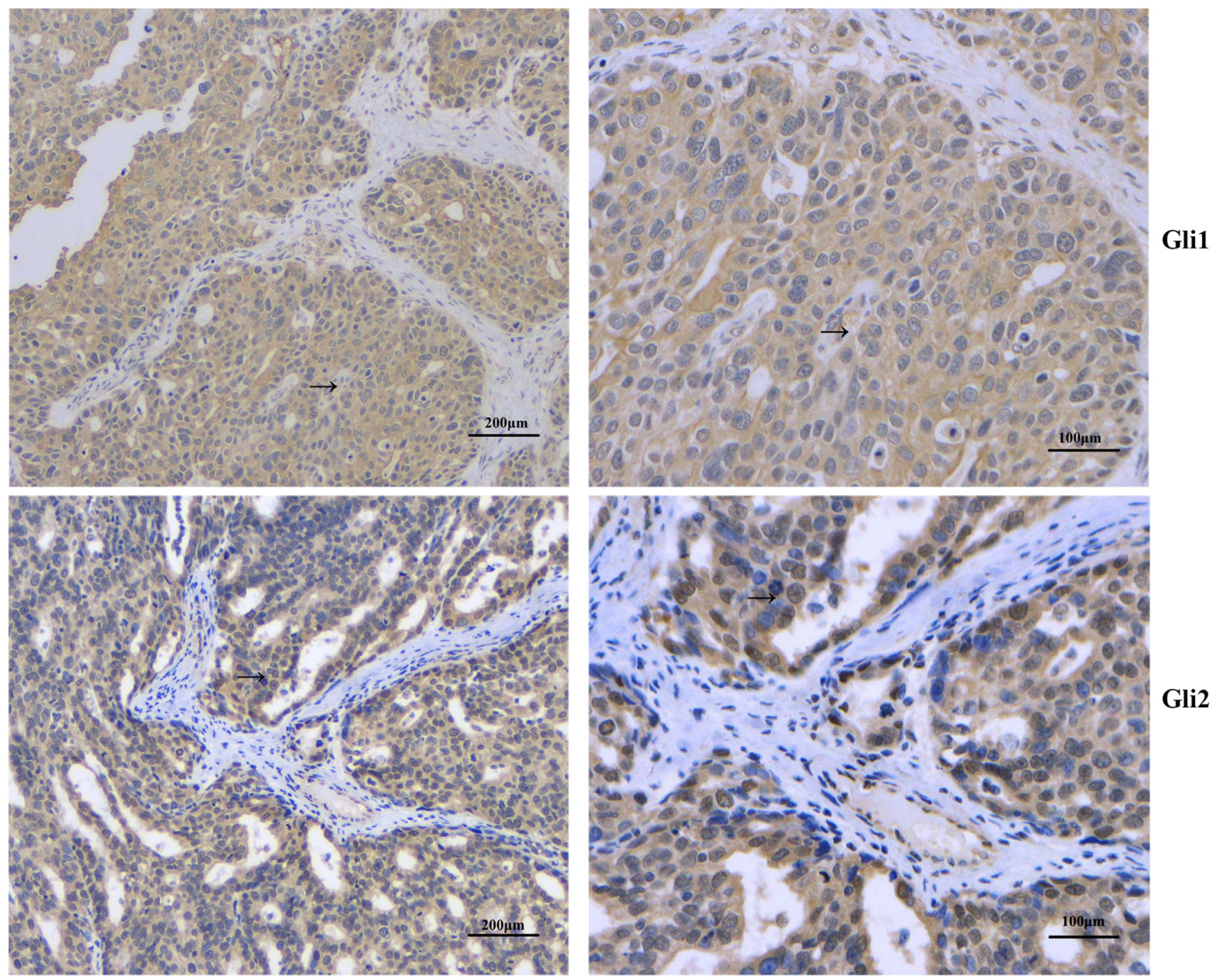

Gli2

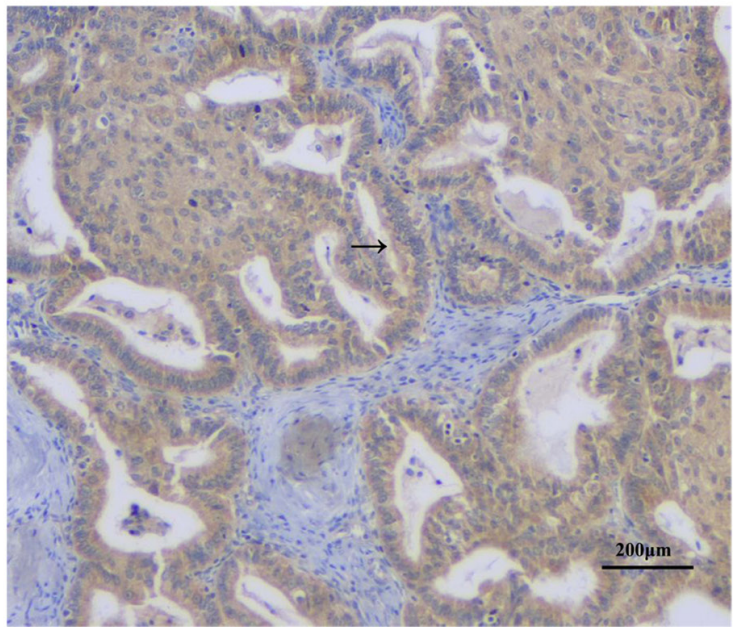

$\times \mathbf{2 0 0}$

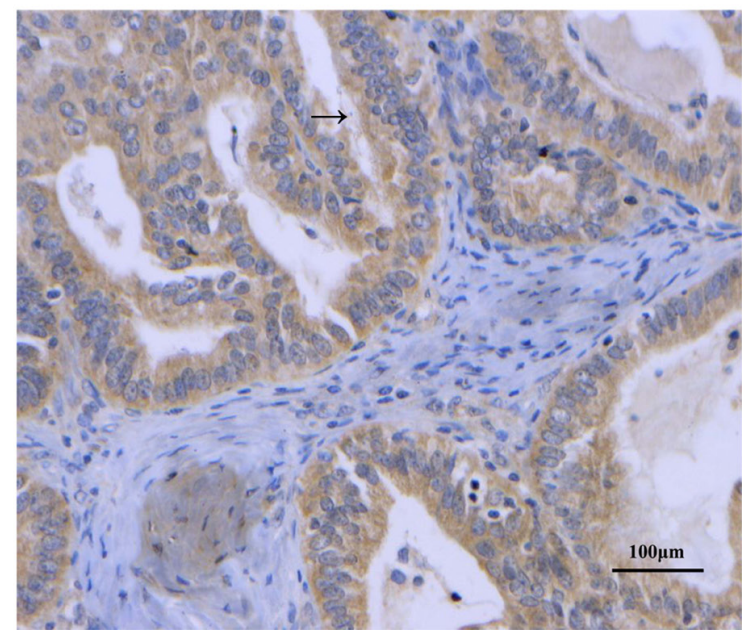

$\times 400$

\section{NANOG}

Figure 1.Protein expression in epithelial ovarian cancer tissue by immunohistochemistry. The arrow indicates the positive protein expression. Magnification, $\mathrm{x} 200$ and $\mathrm{x} 400$. Scale bar, 100 and $200 \mu \mathrm{m}$. NANOG, homeobox protein NANOG.

In advanced EOC, the proportion of $\mathrm{Gli1}^{+}$cases was higher compared with Gli1 ${ }^{-}$cases $(\mathrm{P}=0.023)$ (Fig. 1; Table I).

The nuclear expression of Gli1 was low, with only 12 cases (19.67\%) exhibiting nuclear localization. Nuclear Gli1 expression was not significantly associated with any clinicopathological features $(\mathrm{P}>0.05)$ (Table I).

By contrast, Gli2 was expressed in both the cytoplasm and nucleus of EOC samples. A total of 34 cases tested Gli2 ${ }^{+}$in the cytoplasm (55.74\%). Unlike cytoplasmic Gli1, cytoplasmic
Gli2 expression was not associated with any clinicopathological features $(\mathrm{P}>0.05)$ (Table II).

There were 36 cases $(59.02 \%)$ with positive nuclear expression of Gli2, but there were no significant associations between nuclear Gli2 expression and age, lymph node metastasis, pathological tissue type, disease stage and histopathological grade $(\mathrm{P}>0.05)$. However, nuclear Gli2 expression was significantly associated with platinum resistance in patients with EOC (Table II). Among the platinum-resistant cases, there 
Table I. Association between Gli1 expression and the clinical and pathological characteristics of patients with EOC.

\begin{tabular}{|c|c|c|c|c|c|c|c|c|c|}
\hline \multirow[b]{2}{*}{ Parameter } & \multirow[b]{2}{*}{$\mathrm{n}$} & \multicolumn{2}{|c|}{ Gli1 expression } & \multirow[b]{2}{*}{$\chi^{2}$} & \multirow[b]{2}{*}{ P-value } & \multicolumn{2}{|c|}{$\begin{array}{l}\text { Nuclear Gli1 } \\
\text { expression }\end{array}$} & \multirow[b]{2}{*}{$\chi^{2}$} & \multirow[b]{2}{*}{ P-value } \\
\hline & & Positive & Negative & & & Positive & Negative & & \\
\hline Age, years & & & & 0.752 & 0.386 & & & 0.411 & 0.734 \\
\hline$<50$ & 20 & 14 & 6 & & & 3 & 17 & & \\
\hline$\geq 50$ & 41 & 24 & 17 & & & 9 & 32 & & \\
\hline Tissue type & & & & 4.197 & 0.296 & & & 0.393 & 0.943 \\
\hline Serous & 38 & 24 & 14 & & & 7 & 31 & & \\
\hline Mucinous & 10 & 4 & 6 & & & 2 & 8 & & \\
\hline Endometrioid & 10 & 7 & 3 & & & 2 & 8 & & \\
\hline Other & 3 & 3 & 0 & & & 1 & 2 & & \\
\hline Stage & & & & 5.152 & 0.023 & & & 0.588 & 0.518 \\
\hline I-II & 21 & 9 & 12 & & & 3 & 18 & & \\
\hline III-IV & 40 & 29 & 11 & & & 9 & 31 & & \\
\hline Histological grade & & & & 1.340 & 0.247 & & & 1.605 & 0.309 \\
\hline G1 & 21 & 11 & 10 & & & 6 & 15 & & \\
\hline G2-G3 & 40 & 27 & 13 & & & 6 & 34 & & \\
\hline Lymph node metastasis & & & & 0.831 & 0.362 & & & 2.706 & 0.182 \\
\hline Yes & 23 & 16 & 7 & & & 7 & 16 & & \\
\hline No & 38 & 22 & 16 & & & 5 & 33 & & \\
\hline Platinum sensitivity & & & & 6.752 & 0.009 & & & 1.415 & 0.287 \\
\hline Resistant & 17 & 15 & 2 & & & 5 & 7 & & \\
\hline Sensitive & 44 & 23 & 21 & & & 12 & 37 & & \\
\hline
\end{tabular}

Cytoplasmic expression of Gli1 is associated with the pathological surgical stage $\left(\chi^{2}=5.152, \mathrm{P}=0.023\right)$ and platinum resistance $\left(\chi^{2}=6.752\right.$, $\mathrm{P}=0.009)$, whereas nuclear Gli1 expression is not significantly associated with any clinicopathological characteristics. EOC, epithelial ovarian cancer.

were significantly more patients with nuclear $\mathrm{Gli}^{+}$compared with nuclear Gli2- expression $(\mathrm{P}<0.001)$.

Among the 61 patients with EOC, there were $36 \mathrm{NANOG}^{+}$ cases $(59.0 \%)$, and the protein was mainly expressed in the cytoplasm (Fig. 1). There was no significant difference in expression between different age groups $(\mathrm{P}>0.05)$. Although there was no significant association with lymph node metastasis, tumor differentiation or histological type $(\mathrm{P}>0.05)$, NANOG expression was associated with disease staging and platinum resistance, and its expression rate increased upon increasing stage $(\mathrm{P}<0.001)$. $\mathrm{NANOG}^{-}$cases were more sensitive to platinum-based therapy, whereas $\mathrm{NANOG}^{+}$ cases were significantly drug-resistant $(\mathrm{P}=0.021)$ (Fig. 1; Table III).

Correlation of Gli expression with NANOG in EOC tissue. The protein expression of Gli1 in the cytoplasm was significantly positively correlated with that of NANOG in EOC tissues $(r=0.796 ; \mathrm{P}<0.001)$. Cytoplasmic Gli2 expression was also significantly positively correlated with NANOG levels $(\mathrm{r}=0.264 ; \mathrm{P}=0.039)$. However, there was no statistically significant correlation between nuclear Gli2 expression and NANOG levels $(r=0.187 ; \mathrm{P}=0.145)$ (Table IV).
Gli and NANOG expression are negatively associated with EOC patient survival. Kaplan-Meier analysis showed that the median survival time of the cytoplasmic Gli1 ${ }^{+}$group was 32 months, and that of the cytoplasmic Gli1' group was 68 months. There was a significant difference in survival rates between the two groups $\left(\chi^{2}=8.892 ; \mathrm{P}=0.003\right)$ (Fig. 2A). There was no significant difference in survival rates between the nuclear $\mathrm{Gli1}^{+}$and nuclear Gli1 ${ }^{-}$groups $(\mathrm{P}=0.207)$ (data not shown).

The median survival time of the nuclear Gli2 $2^{+}$group was 30 months, and that of the Gli2 group was 68 months, which also showed a significant difference $\left(\chi^{2}=11.717 ; \mathrm{P}=0.001\right)$ (Fig. 2B). No significant difference was found in survival rates between the cytoplasmic Gli2 ${ }^{+}$and cytoplasmic Gli2- groups $(\mathrm{P}=0.302)$ (data not shown).

Similar to the results of Gli1 and Gli2, the median survival duration of the $\mathrm{NANOG}^{+}$group was 32 months, and that of the NANOG- group was 69 months. There was a significant difference in survival between the two groups $\left(\chi^{2}=14.824\right.$; $\mathrm{P}<0.001$ ) (Fig. 2C).

The effects of all three markers on survival were further analyzed. Three groups were excluded due to low sample numbers from the analysis. The remaining four groups (55 cases) were analyzed, and the results showed that the 
Table II. Association between Gli2 expression and the clinical and pathological characteristics of patients with EOC.

\begin{tabular}{|c|c|c|c|c|c|c|c|c|c|}
\hline \multirow[b]{2}{*}{ Parameter } & \multirow[b]{2}{*}{$\mathrm{n}$} & \multicolumn{2}{|c|}{ Gli2 expression } & \multirow[b]{2}{*}{$\chi^{2}$} & \multirow[b]{2}{*}{ P-value } & \multicolumn{2}{|c|}{$\begin{array}{c}\text { Nuclear Gli2 } \\
\text { expression }\end{array}$} & \multirow[b]{2}{*}{$\chi^{2}$} & \multirow[b]{2}{*}{ P-value } \\
\hline & & Positive & Negative & & & Positive & Negative & & \\
\hline Age, years & & & & 0.007 & 0.935 & & & 0.198 & 0.656 \\
\hline$<50$ & 20 & 11 & 9 & & & 11 & 9 & & \\
\hline$\geq 50$ & 41 & 23 & 18 & & & 25 & 16 & & \\
\hline Tissue type & & & & 3.684 & 0.298 & & & 2.443 & 0.486 \\
\hline Serous & 38 & 20 & 18 & & & 22 & 16 & & \\
\hline Mucinous & 10 & 4 & 6 & & & 6 & 4 & & \\
\hline Endometrioid & 10 & 8 & 2 & & & 5 & 5 & & \\
\hline Other & 3 & 2 & 1 & & & 3 & 0 & & \\
\hline Stage & & & & 0.856 & 0.355 & & & 3.457 & 0.063 \\
\hline I-II & 21 & 10 & 11 & & & 9 & 12 & & \\
\hline III-IV & 40 & 24 & 16 & & & 27 & 13 & & \\
\hline Histological grade & & & & 0.556 & 0.355 & & & 0.583 & 0.445 \\
\hline G1 & 21 & 10 & 11 & & & 11 & 10 & & \\
\hline G2-G3 & 40 & 24 & 16 & & & 25 & 15 & & \\
\hline Lymph node metastasis & & & & 0.190 & 0.663 & & & 0.191 & 0.662 \\
\hline Yes & 23 & 12 & 11 & & & 14 & 9 & & \\
\hline No & 38 & 22 & 16 & & & 22 & 16 & & \\
\hline Platinum sensitivity & & & & 2.107 & 0.147 & & & 16.367 & $<0.001$ \\
\hline Resistant & 17 & 12 & 5 & & & 17 & 0 & & \\
\hline Sensitive & 44 & 22 & 22 & & & 19 & 25 & & \\
\hline
\end{tabular}

Cytoplasmic Gli2 expression is not associated with the investigated clinicopathological characteristics of patients with EOC, while nuclear Gli2 expression is associated with platinum resistance in patients with EOC $\left(\chi^{2}=16.367, \mathrm{P}<0.001\right)$. EOC, epithelial ovarian cancer.

median survival duration of the cytoplasmic Gli1 ${ }^{+}$, nuclear $\mathrm{Gli}^{+}$and $\mathrm{NANOG}^{+}$group was 26 months, the cytoplasmic $\mathrm{Gli1}^{+}$, nuclear Gli2 ${ }^{-}$and $\mathrm{NANOG}^{+}$group was 45 months, the cytoplasmic Gli1', nuclear $\mathrm{Gli2}^{+}$and $\mathrm{NANOG}^{-}$group was 48 months and the cytoplasmic Gli1' ${ }^{-}$, nuclear Gli2 ${ }^{-}$and NANOG $^{-}$group was 69 months. Overall, Gli1, Gli2 and NANOG expression were significantly associated with reduced survival of patients with $\mathrm{EOC}\left(\chi^{2}=19.669 ; \mathrm{P}<0.001\right)$ (Fig. 2D). Cox regression was applied to analyze the effects of cytoplasmic Gli1, nuclear Gli2 and NANOG expression on survival. The results showed that the expression of nuclear Gli2 and NANOG are independent prognostic factors for the survival time of patients. The survival time of nuclear Gli2 ${ }^{+}$ patients $(\mathrm{P}=0.001$; HR, 2.896; 95\% CI, 1.520-5.517) and $\mathrm{NANOG}^{+}$patients $(\mathrm{P}=0.002$; HR, 2.857; 95\% CI, 1.470-5.550) are shorter (Table V).

Expression of molecules in ovarian cancer cells after treatment with GANT61. Following treatment with the Gli1 and Gli2 inhibitor GANT61, the expression of Gli1, Gli2 and NANOG were detected via RT-qPCR and western blotting in ovarian cancer cells. The results showed that Gli1 and Gli2 expression significantly decreased as expected, as did the levels of NANOG (Fig. 3A and B). In addition, after treatment with GANT61 and SHH, the expression of the drug-resistance associated transporter, MDR1, in SKOV3 cells was also examined. GANT61 treatment resulted in a decrease in MDR1 levels (Fig. 3A and B).

Gli promotes ovarian cancer cell proliferation. The results of the CCK-8 assays showed that the proliferation rate of SKOV3 cells in the GANT61 treatment group decreased in a time- and concentration-dependent manner. After $24 \mathrm{~h}$, the $100 \mu \mathrm{mol} / 1$ group showed a $37.69 \%$ decrease in proliferation compared with the control group. When cells were treated with $50 \mu \mathrm{mol} / 1$ GANT61 for $48 \mathrm{~h}$, the optical density (OD) value decreased by $27 \%$, while the $100 \mu \mathrm{mol} / 1$ group showed a $72 \%$ decrease in the OD value. After $72 \mathrm{~h}$, the 20,50 and $100 \mu \mathrm{mol} / 1$ groups showed $12.6,45$ and $80 \%$ decreases in the OD value, respectively (Fig. 4A). Collectively, this suggested that Gli inhibition via GANT61 treatment reduced ovarian cancer cell proliferation.

Gli promotes the colony-formation ability of SKOV3 cells. The results of the plate colony formation assay showed that the colony-forming ability of SKOV3 cells treated with GANT61 was significantly lower compared with the control group (69.6 vs. 25.1\%; Fig. 5A, B and D), indicating that Gli inhibition reduced colony formation of ovarian cancer cells. 
Table III. Association between NANOG expression and the clinical and pathological characteristics of patients with epithelial ovarian cancer.

\begin{tabular}{|c|c|c|c|c|c|}
\hline \multirow[b]{2}{*}{ Parameter } & \multirow[b]{2}{*}{$\mathrm{n}$} & \multicolumn{2}{|c|}{ NANOG expression } & \multirow[b]{2}{*}{$\chi^{2}$} & \multirow[b]{2}{*}{ P-value } \\
\hline & & Positive & Negative & & \\
\hline Age, years & & & & 0.440 & 0.507 \\
\hline$<50$ & 20 & 13 & 7 & & \\
\hline$\geq 50$ & 41 & 23 & 18 & & \\
\hline Tissue type & & & & 1.841 & 0.606 \\
\hline Serous & 38 & 24 & 14 & & \\
\hline Mucinous & 10 & 4 & 6 & & \\
\hline Endometrioid & 10 & 6 & 4 & & \\
\hline Other & 3 & 2 & 1 & & \\
\hline Stage & & & & 12.273 & $<0.001$ \\
\hline I-II & 21 & 6 & 15 & & \\
\hline III-IV & 40 & 30 & 10 & & \\
\hline Histological grade & & & & 3.457 & 0.063 \\
\hline G1 & 21 & 9 & 12 & & \\
\hline G2-G3 & 40 & 27 & 13 & & \\
\hline Lymph node metastasis & & & & 1.699 & 0.192 \\
\hline Yes & 23 & 16 & 7 & & \\
\hline No & 38 & 20 & 18 & & \\
\hline Platinum sensitivity & & & & 5.307 & 0.021 \\
\hline Resistant & 17 & 14 & 3 & & \\
\hline Sensitive & 44 & 22 & 22 & & \\
\hline
\end{tabular}

NANOG expression is associated with disease staging $\left(\chi^{2}=12.273, \mathrm{P}<0.001\right)$ and platinum resistance $\left(\chi^{2}=5.307, \mathrm{P}=0.021\right)$ in patients with EOC. EOC, epithelial ovarian cancer; NANOG, homeobox protein NANOG.

Table IV. Correlation between Gli expression and NANOG in EOC tissue.

\begin{tabular}{|c|c|c|c|c|c|}
\hline \multirow[b]{2}{*}{ Gli expression } & \multicolumn{2}{|c|}{ NANOG expression } & \multirow[b]{2}{*}{ Total, n (\%) } & \multirow[b]{2}{*}{ P-value } & \multirow[b]{2}{*}{ r-value } \\
\hline & Positive, n (\%) & Negative, n (\%) & & & \\
\hline Cytoplasmic Gli1 & $36(59.0)$ & $25(41.0)$ & $61(100)$ & $<0.001^{\mathrm{a}}$ & 0.796 \\
\hline Positive & $34(55.7)$ & $4(6.5)$ & $38(62.3)$ & & \\
\hline Negative & $2(3.3)$ & $21(34.4)$ & $23(37.7)$ & & \\
\hline Nuclear Gli1 & $36(59.0)$ & $25(41.0)$ & $61(100)$ & 0.397 & 0.077 \\
\hline Positive & $8(13.1)$ & $4(6.6)$ & $12(19.7)$ & & \\
\hline Negative & $28(45.9)$ & $21(34.4)$ & $49(80.3)$ & & \\
\hline Cytoplasmic Gli2 & $36(59.0)$ & $25(41.0)$ & $61(100)$ & $0.039^{\mathrm{a}}$ & 0.264 \\
\hline Positive & $24(39.3)$ & $10(16.4)$ & $34(55.7)$ & & \\
\hline Negative & $12(19.7)$ & $15(24.6)$ & $27(44.3)$ & & \\
\hline Nuclear Gli2 & $12(19.7)$ & $13(21.3)$ & $25(41.0)$ & 0.145 & 0.187 \\
\hline Positive & $24(39.3)$ & $12(19.7)$ & $36(59.0)$ & & \\
\hline Negative & $36(59.0)$ & $25(41.0)$ & $61(100)$ & & \\
\hline
\end{tabular}

The expression of Gli1 and Gli2 in the cytoplasm was significantly positively correlated with that of NANOG in EOC tissues ( ${ }^{\mathrm{a} P}<0.05$ ). EOC, epithelial ovarian cancer; NANOG, homeobox protein NANOG.

GANT61 reverses cisplatin resistance in ovarian cancer cells. The $\mathrm{IC}_{50}$ of cisplatin against SKOV3 cells in response to different treatments groups was assessed using the CCK-8 assay. The results showed that the $\mathrm{IC}_{50}$ of cisplatin after $24 \mathrm{~h}$ 
A Overall survival of patients with positive or negative expression of

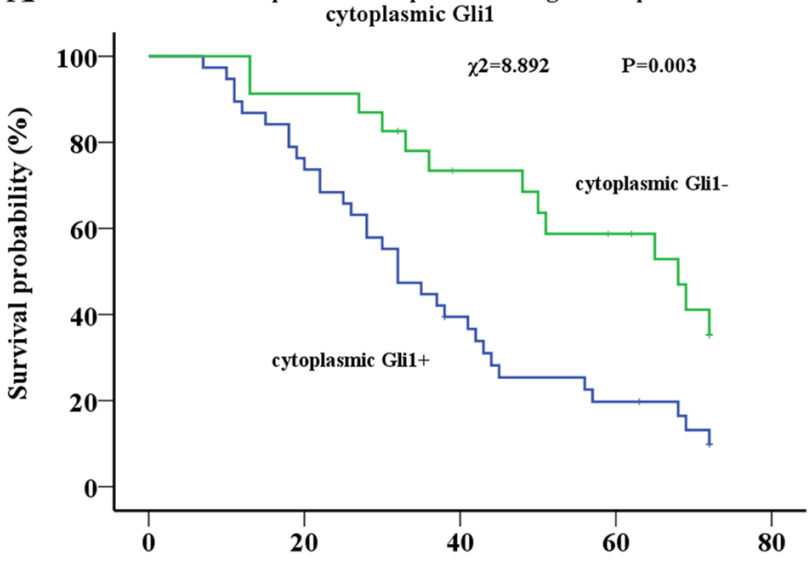

Months

C Overall survival of patients with positive or negative expression of NANOG

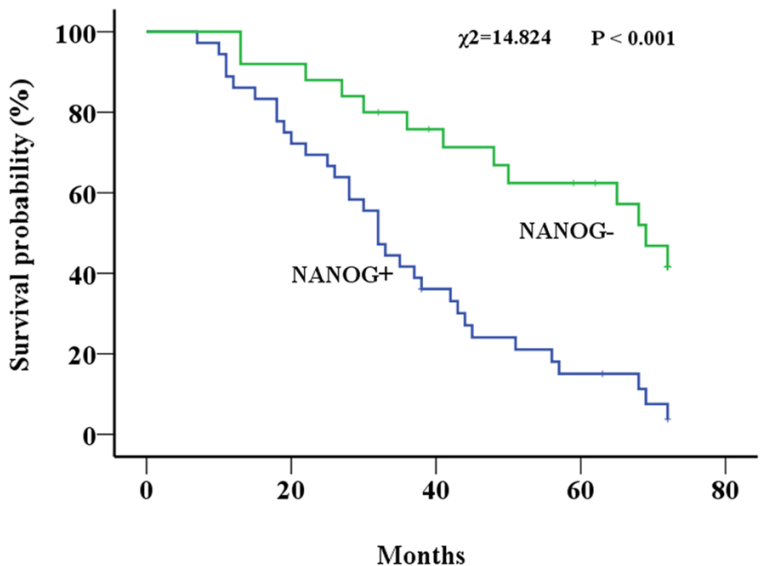

B Overall survival of patients with positive or negative expression of nuclear Gli2

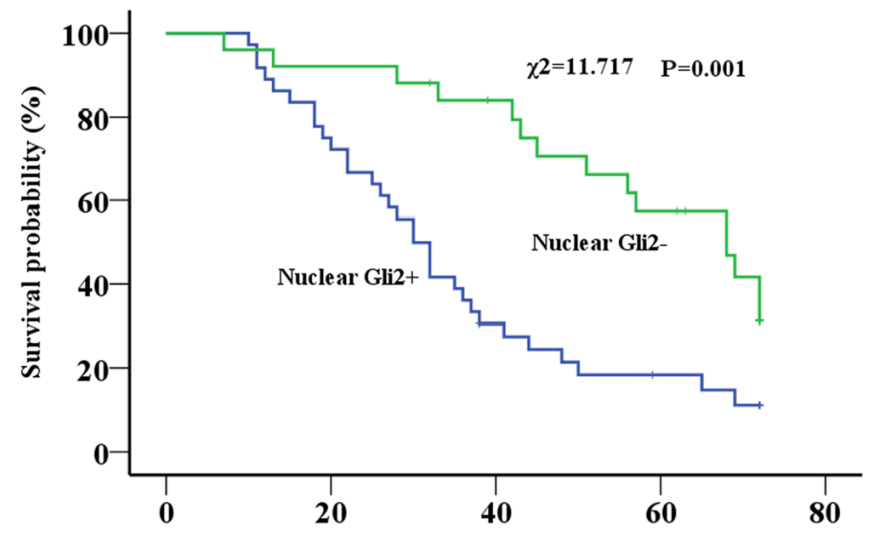

Months

D Overall survival of patients with positive or negative expression of Gli1 Gli2 and NANOG

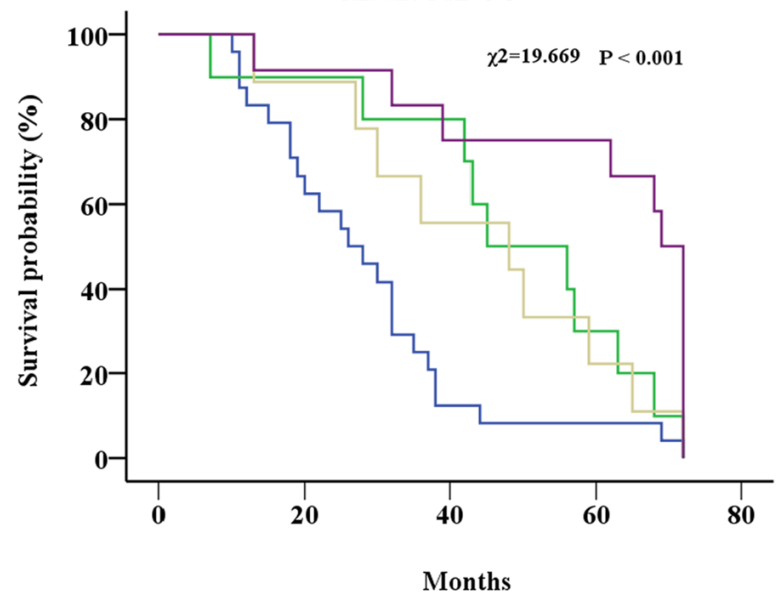

Figure 2. Survival analysis of patients with EOC. (A) Survival analysis of patients with EOC with low (green line) and high (blue line) expression of cytoplasmic Gli1. (B) Survival analysis of patients with EOC with low (green line) and high (blue line) expression of nuclear Gli2. (C) Survival analysis of patients with EOC with low (green line) and high (blue line) expression of NANOG. (D) Survival analysis of patients with EOC with cytoplasmic Gli1 ${ }^{+}$, nuclear $\mathrm{Gli}^{+}$and $\mathrm{NANOG}^{+}$(blue line), cytoplasmic Gli1 ${ }^{+}$, nuclear Gli2 ${ }^{-}$and $\mathrm{NANOG}^{+}$(yellow line), cytoplasmic Gli1 ${ }^{-}$, nuclear Gli2 ${ }^{+}$and NANOG ${ }^{-}$(green line), and cytoplasmic Gli1', nuclear Gli2- and NANOG- (purple line). EOC, epithelial ovarian cancer; NANOG, homeobox protein NANOG.

\section{A Gene expression in SKOV3 cells after treatment with GANT61 and SHH}

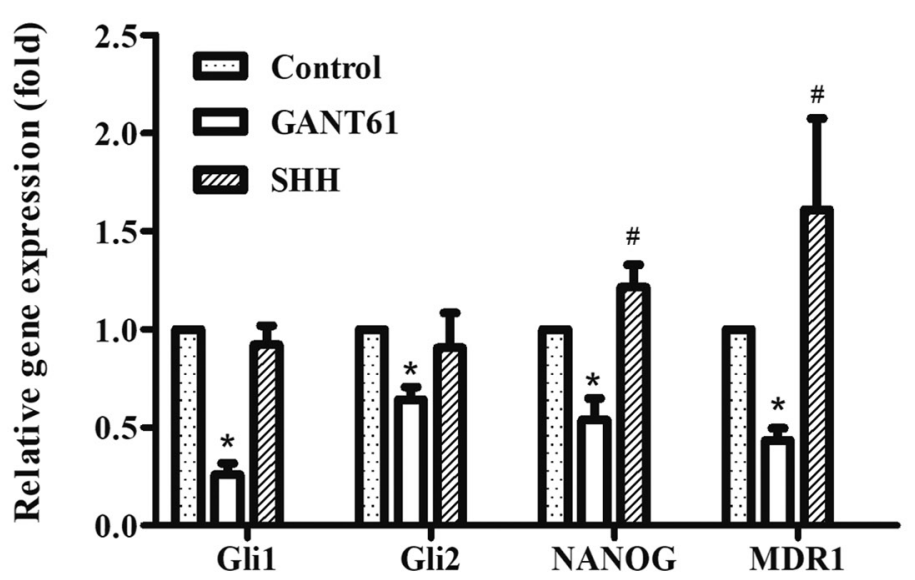

\section{B GANT61 Control SHH}

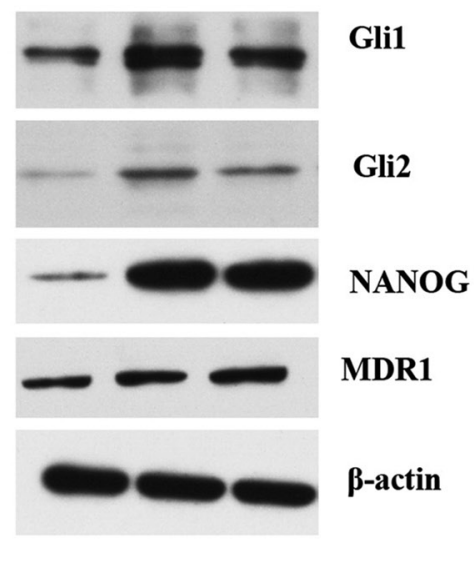

Figure 3. Gene expression in different treatment groups. (A) Gli1, Gli2, NANOG and MDR1 expression were decreased after treatment with GANT61 in SKOV3 cells. mRNA expression of Gli1 and Gli2 did not significantly change in SKOV3 cells, while mRNA expression of NANOG and MDR1 increased slightly after treatment with SHH. (B) The expression of Gli1, Gli2, NANOG and MDR1 in SKOV3 cells after treatment with GANT61 and SHH was detected by western blotting. "P<0.05 vs. control; " $\mathrm{P}<0.05$ vs. control. EOC, epithelial ovarian cancer; NANOG, homeobox protein NANOG; MDR1, p-glycoprotein; $\mathrm{SHH}$, recombinant human sonic $\mathrm{HH}$. 
A

Proliferation of SKOV3 cells after treatment with different concentrations of GANT61

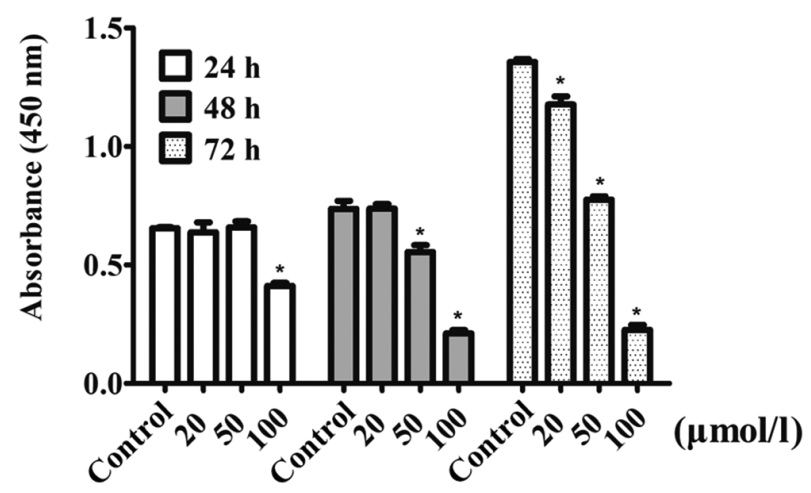

B Proliferation of SKOV3 cells after treatment with different concentrations of $\mathrm{SHH}$

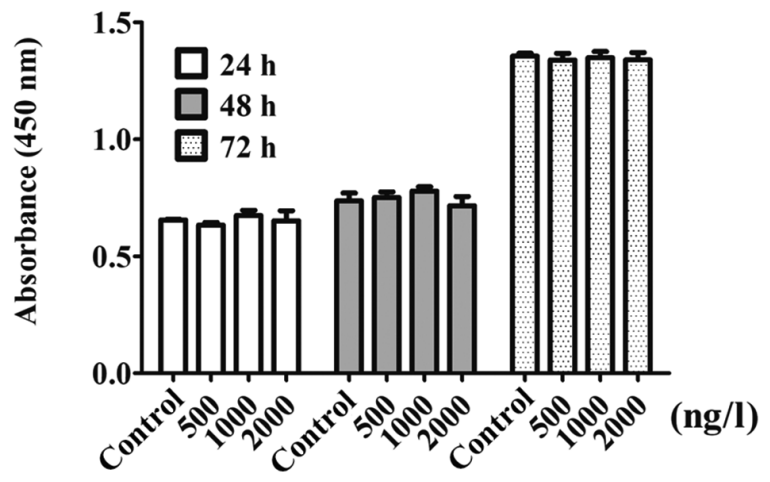

Figure 4. Proliferative ability after treatment with GANT61 and SHH. (A) The proliferation of SKOV3 cells decreased after treatment with GANT61 at a concentration of $100 \mu \mathrm{mol} / \mathrm{l}$ in the $24 \mathrm{~h}$ group and decreased after treatment with GANT61 at a concentration of 50 and $100 \mu \mathrm{mol} / 1$ in the 48 and $72 \mathrm{~h}$ groups. The effect was time- and concentration-dependent. (B) The proliferation of SKOV3 cells did not change significantly after treatment with SHH (using concentrations of 500, 1,000 and 2,000 ng/l). "P<0.05 vs. control group. SHH, recombinant human sonic HH.

Table V. Effects of nuclear Gli2 and NANOG expression on survival of patients with EOC determined by Cox regression analysis.

\begin{tabular}{lccc}
\hline Group & P-value & HR & $95 \%$ CI \\
\hline Nuclear Gli2 $^{+}$ & $0.001^{\mathrm{a}}$ & 2.896 & $1.520-5.517$ \\
NANOG $^{+}$ & $0.002^{\mathrm{a}}$ & 2.857 & $1.470-5.550$ \\
\hline
\end{tabular}

${ }^{\text {a }} \mathrm{P}<0.05$ vs. negative gene expression group. EOC, epithelial ovarian cancer; NANOG, homeobox protein NANOG.

decreased from $3.151 \pm 0.289$ to $0.517 \pm 0.022 \mu \mathrm{g} / \mathrm{ml}$ in the GANT61 group (Fig. 6A and D). The $\mathrm{IC}_{50}$ further decreased from $1.121 \pm 0.050$ to $0.050 \pm 0.012 \mu \mathrm{g} / \mathrm{ml}$ after $48 \mathrm{~h}$ of cisplatin treatment (Fig. 6B and D). The $\mathrm{IC}_{50}$ decreased from $0.368 \pm 0.102$ to $0.073 \pm 0.012 \mu \mathrm{g} / \mathrm{ml}$ after GANT61 treatment for $72 \mathrm{~h}$ (Fig. 6C and D). The results indicated that SKOV3 cells were significantly more sensitive to cisplatin after inhibition of Gli1 and Gli2 (Fig. 6).

Exogenous SHH did not exert a significant effect on Gli, cell proliferation and cisplatin sensitivity in EOC. The present study exogenously added recombinant human SHH protein to increase the expression of Gli by activation of the HH signaling pathway. Compared with the control group, the addition of exogenous SHH did not affect cell proliferation and sensitivity to cisplatin, as expected (Figs. 4B and 6A-C). RT-qPCR and western blot analysis showed that the addition of exogenous SHH did not result in an increase in Gli1 and Gli2, and even caused a slight decrease in these two proteins compared with the control group. SHH treatment only resulted in a slight increase in NANOG and MDR1 levels compared with the control group (Fig. 3A and B). Plate cloning experiments showed that the addition of SHH slightly reduced the colony formation rate of the cells, compared with the control group, from 69.6 to $58.3 \%$ (Fig. 5C and D).

\section{Discussion}

The HH signaling pathway is an evolutionarily conserved signaling pathway (3). A number of studies have demonstrated that $\mathrm{HH}$ signaling is closely associated with the occurrence and development of numerous malignant tumors (3-6). Although the medical community has made a number of advances in the treatment of ovarian cancer, chemoresistance is still an important issue that affects the treatment and survival rate of patients (1). Despite investigation into $\mathrm{HH}$ signaling in tumor chemoresistance, there is still controversy regarding the role of Gli in platinum resistance. Some studies have reported that Gli1 is closely associated with tumor resistance $(11,12)$, while other results suggested that Gli2, but not Gli1, may have more predictive value (13). The present results showed that Gli1 and Gli2 are both involved in platinum resistance of ovarian cancer, but the nuclear expression of Gli2 appears to be a more appropriate marker for predicting platinum resistance. Since Gli is a transcription factor and thus functions in the nucleus, nuclear protein expression is more likely to represent active signaling (21). Therefore, nuclear expression of Gli1 and Gli2 was assessed in a separate statistical analysis. The results showed that while the nuclear expression rate of Gli1 was not high, Gli2 expression was much higher. There was also a significant association between nuclear Gli2 expression and platinum resistance. The results from the present study suggested that positive nuclear expression of Gli2 may be a more appropriate marker of platinum resistance in ovarian cancer. Previous studies on the location of Gli expression in tumors have also found that although nuclear expression may be activated in a stricter sense, cytoplasmic expression is also associated with some clinicopathological characteristics, but the reason is not clear $(21,22)$. It may be caused by the interaction between Gli1 and Gli2, and the non-canonical pathway $(10,23)$. The present study also observed that the expression of Gli1 and Gli2 in the cytoplasm is closely associated with the clinical and pathological characteristics of drug resistance and stage, which implies the importance of Gli1 and Gli2, as well as the non-canonical HH pathway in EOC. 
A

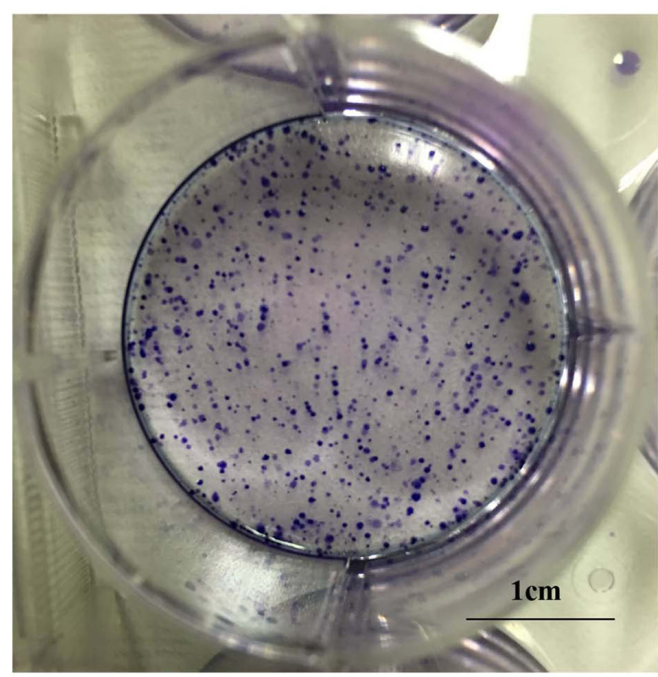

C

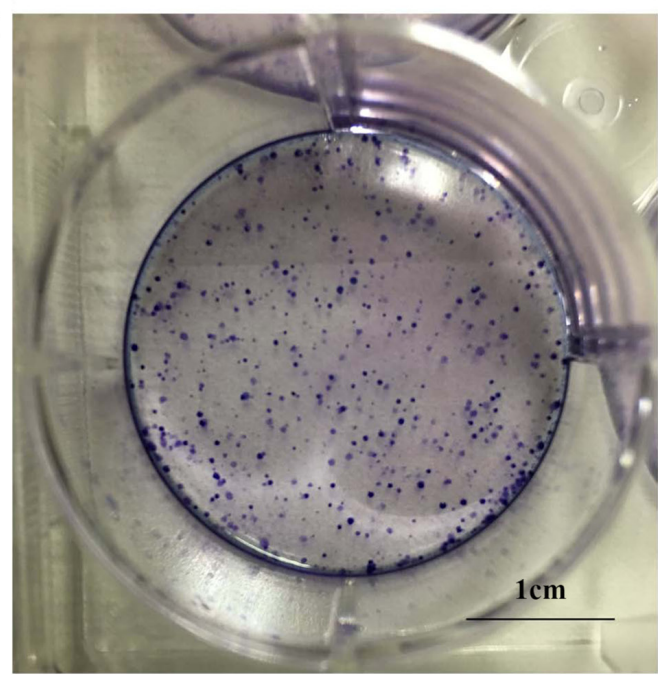

B

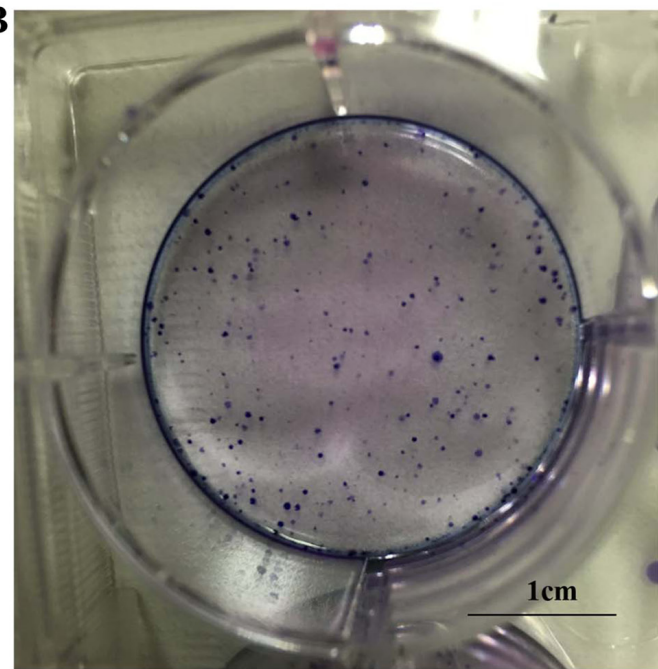

D

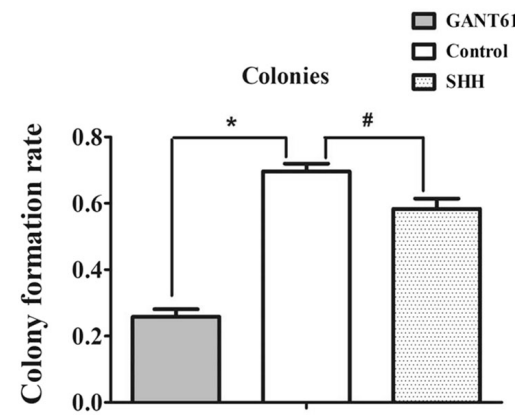

Figure 5. Colony formation after treatment with SHH and GANT61. (A) Colony formation assay of SKOV3 cells without treatment. (B) Colony formation assay of SKOV3 cells after treatment with GANT61. (C) Colony formation assay of SKOV3 cells after treatment with SHH. Scale bar, $1 \mathrm{~cm}$. (D) Colony formation of different groups. ${ }^{*} \mathrm{P}<0.05 ;{ }^{*} \mathrm{P}<0.05$. SHH, recombinant human sonic $\mathrm{HH}$.

Therefore, the determination of Gli activation status requires further research to be fully understood.

The present in vitro results showed that after SKOV3 cells were treated with the HH inhibitor GANT61, the sensitivity of the cells to cisplatin was significantly increased, suggesting that Gli promoted platinum resistance in ovarian cancer cells. MDR1 expression was also decreased, which supported the effects of Gli on drug resistance of EOC. As a key factor in the HH signaling pathway, Glil is associated with the stage, differentiation and poor prognosis of a variety of tumors (23-26). The results of the present study confirmed those of previous studies. The present study showed that Gli1 expression was associated with the stage of the disease, but no difference was found according to different degrees of differentiation, and it was speculated that there may be a bias caused by the small sample size. The present in vitro results also demonstrated that targeting Gli reduced cell proliferation and colony formation. The stem cell theory of cancer proposes that cancer stem cells have stronger drug resistance, proliferation and colony-forming ability, and possess several unique markers, such as CD44, CD133, aldehyde dehydrogenase (ALDH) and NANOG (4,5,7). Previous studies have suggested using CD44, CD133 and ALDH as ovarian cancer stem cell markers for experimental research and stem cell identification $(4,7)$. Thus far, only a few studies have suggested using NANOG as an ovarian cancer stem cell marker (27). NANOG is a pluripotent factor, which is reported to regulate cell self-renewal and chemotherapy resistance in some tumors $(14,15)$. NANOG was also reported to be a downstream target of Gli (16). The present immunohistochemistry results showed that NANOG expression was associated with platinum resistance and the stage of the disease stage. The results also showed a significant correlation between NANOG and cytoplasmic Gli1 and Gli2 expression. In the present study, a corresponding decrease in NANOG expression was observed following inhibition of Gli1 and Gli2 expression in SKOV3 cells. The results of the present study suggested that the stemness of ovarian cancer may be altered by inhibiting the Gli-NANOG pathway, which may be one of the mechanisms via which $\mathrm{HH}$ signaling is involved in tumor stem cells. The application of targeted inhibition of Gli expression may reverse proliferative capacity, chemoresistance and colony formation rate of tumors by regulating tumor stem cell formation. 
A

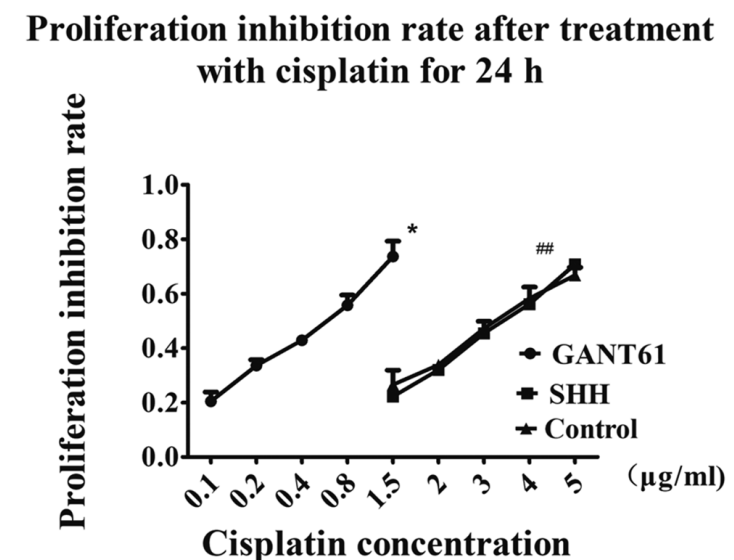

C

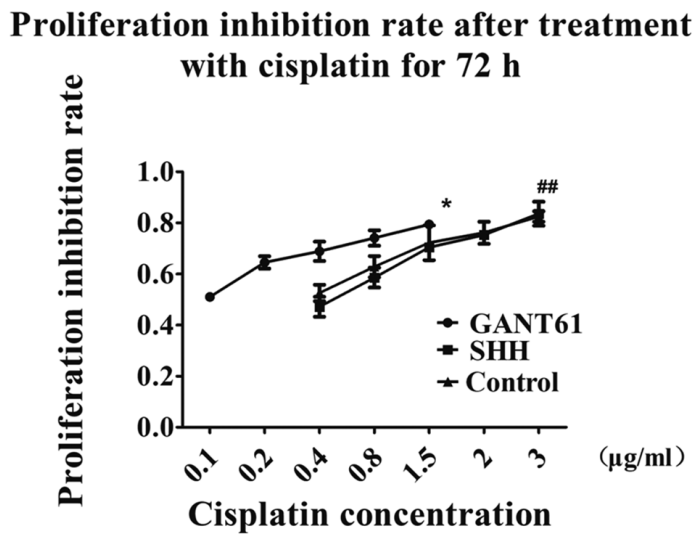

B

Proliferation inhibition rate after treatment with cisplatin for $48 \mathrm{~h}$

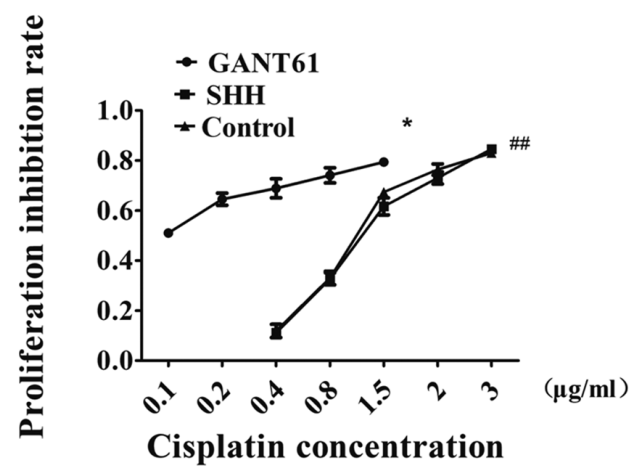

D

$\mathrm{IC}_{50}$ of cisplatin against $\mathrm{SKOV} 3$ cells in
response to different treatments groups

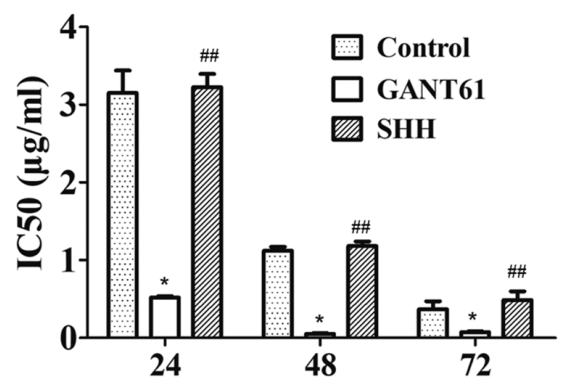

Figure 6. Sensitivity to cisplatin in different treatment groups. (A) The proliferation inhibition rate was higher in the GANT61 group than in the SHH and control groups, and the $\mathrm{IC}_{50}$ decreased from $3.151 \pm 0.289$ to $0.517 \pm 0.022 \mu \mathrm{g} / \mathrm{ml}$ after GANT61 treatment for $24 \mathrm{~h}$. (B) The proliferation inhibition rate was higher in the GANT61 group than in the SHH and control groups, and the $\mathrm{IC}_{50}$ decreased from $1.121 \pm 0.050$ to $0.050 \pm 0.012 \mu \mathrm{g} / \mathrm{ml}$ after GANT61 treatment for $48 \mathrm{~h}$. (C) The proliferation inhibition rate was higher in the GANT61 group than in the SHH and control groups, and the $\mathrm{IC}_{50}$ decreased from $0.368 \pm 0.102$ to $0.073 \pm 0.012 \mu \mathrm{g} / \mathrm{ml}$ after GANT61 treatment for $72 \mathrm{~h}$. (D) The $\mathrm{IC}_{50}$ of cisplatin against SKOV3 cells in response to different treatments groups. "P<0.05 vs. control; ${ }^{\# \#} \mathrm{P}>0.05$ vs. control. SHH, recombinant human sonic $\mathrm{HH}$

Kaplan-Meier survival analysis showed that patients with cytoplasmic Gli1, nuclear Gli2 and NANOG expression had worse survival rates. Cox regression showed that nuclear Gli2 and NANOG are independent prognostic factors for the survival time of patients with EOC, suggesting that these three markers, especially nuclear Gli2 and NANOG, can be used to predict patient outcomes.

In the present study, $\mathrm{SHH}$ was used to activate $\mathrm{HH}$ signaling and result in the expression of Gli, but the exogenous addition of SHH did not cause significant changes in Gli1 and Gli2, as expected. SHH did not cause changes in cell proliferation or sensitivity to cisplatin, but resulted in a slight decrease in colony formation rate. Several research groups reported that the addition of exogenous SHH to different types of tumor cells can result in malignant behaviors, such as cell proliferation, but some have revealed that the addition of exogenous $\mathrm{SHH}$ does not cause similar changes $(23,28)$. This study showed that SKOV3 cells treated with $3 \mathrm{ng} / \mu 1 \mathrm{SHH}$ did not show changes in proliferative capacity or expression of related genes, and even caused a decrease in Gli2. Sabol et al (28) showed that estrogen receptor (ER)-positive cell lines do not respond to $\mathrm{SHH}$ stimulation, suggesting that $\mathrm{ER} \alpha$ regulation is not caused by Gli1 regulation of transcription by SHH. The results from the current study are consistent with the findings that the addition of exogenous SHH does not regulate Gli and its related cellular functions, suggesting the existence of a non-canonical $\mathrm{HH}$ pathway in this model. Furthermore, following the addition of $\mathrm{SHH}$, the expression of NANOG and MDR1 increased slightly. As previous studies have demonstrated, this also confirms the direct participation of other factors and the coexistence of canonical and non-canonical HH pathways $(10,28,29)$.

Although this was the first study investigating the role of Gli and NANOG in EOC and their possible association, it is still necessary to understand the respective roles of Gli1 and Gli2 in the HH pathway and how they interact with NANOG. The interaction of these molecules in other cell lines and their roles in vivo experiments require further study. Additionally, in order to elucidate the functions of Gli, more experiments should be performed in the future to investigate the location of Gli. It is hypothesized in the present study that Gli promotes the development and drug resistance of ovarian cancer via NANOG, both of which are prognostic markers of EOC, as well as indicators of platinum resistance. NANOG may be the key point through which Gli affects stem cell pathways in EOC. Gli inhibition may reverse malignant phenotypes, such as drug resistance, proliferation and the contribution of ovarian cancer stem cells, and may therefore represent a new drug target for the treatment of EOC. 


\section{Acknowledgements}

The authors would like to express their gratitude to Dr Lian Weiguang (Department of Molecular Biology of Hebei Medical University, Shijiazhuang, China) for her help during experiments.

\section{Funding}

This study was funded by the Hebei Health Commission (grant no. 20201011).

\section{Availability of data and materials}

The datasets used and/or analyzed during the current study are available from the corresponding author on reasonable request.

\section{Authors' contributions}

HZ, XW and YP conceived and designed the study. HZ and NL performed the experiments and collected the data. NL and $\mathrm{JZ}$ analyzed and interpreted the data. HZ and YP drafted the manuscript. All authors read and approved the final manuscript.

\section{Ethics approval and consent to participate}

All patients provided written informed consent prior to inclusion in the present study. The ethics committee of The Third Hospital of Hebei Medical University (Shijiazhuang, China) approved the study protocol.

\section{Patient consent for publication}

Not applicable.

\section{Competing interests}

The authors declare that they have no competing interests.

\section{References}

1. da Costa AABA and Baiocchi G: Genomic profiling of platinumresistant ovarian cancer: The road into druggable targets. Semin Cancer Biol 2020: 30221-30222, 2020.

2. Kujawa KA and Lisowska KM: Ovarian cancer-from biology to clinic. Postepy Hig Med Dosw (Online) 69: 1275-1290, 2015 (In Polish).

3. Skoda AM, Simovic D, Karin V, Kardum V, Vranic S and Serman L: The role of the hedgehog signaling pathway in cancer: A comprehensive review. Bosn J Basic Med Sci 18: 8-20, 2018.

4. Wang F, Ma L, Zhang Z, Liu X, Gao H, Zhuang Y, Yang P, Kornmann M, Tian X and Yang Y: Hedgehog signaling regulates epithelial-mesenchymal transition in pancreatic cancer stem-like cells. J Cancer 7: 408-417, 2016.

5. Sun M, Zhang N, Wang X, Li Y, Qi W, Zhang H, Li Z and Yang Q: Hedgehog pathway is involved in nitidine chloride induced inhibition of epithelial-mesenchymal transition and cancer stem cells-like properties in breast cells. Cell Biosci 6: 44, 2016.

6. Xu Y, Song S, Wang Z and Ajani JA: The role of hedgehog signaling in gastric cancer: Molecular mechanisms, clinical potential, and perspective. Cell Commun Signal 17: 157, 2019.

7. Levanat S, Sabol M, Musani V, Ozretic P and Trnski D: Hedgehog signaling pathway as genetic and epigenetic target in ovariantumors. Curr Pharm 23: 73-94, 2017.

8. Coffman LG, Choi YJ, McLean K, Allen BL, di Magliano MP and Buckanovich RJ: Human carcinoma-associated mesenchymal stem cells promote ovarian cancer chemotherapy resistance via a BMP4/HH signaling loop. Oncotarget 7: 6916-6932, 2016.
9. Christensen ST and Ott CM: Cell signaling: A ciliary signaling switch. Science 317: 330-331, 2007.

10. Blotta S, Jakubikova J, Calimeri T, Roccaro AM, Amodio N, Azab AK, Foresta U, Mitsiades CS, Rossi M, Todoerti K, et al: Canonical and noncanonical hedgehog pathway in the pathogenesis of multiple nyeloma. Blood 120: 5002-5013, 2012.

11. Song X, Yan L, Lu C, Zhang C, Zhu F, Yang J, Jing H, Zhang Y, Qiao $\mathrm{J}$ and Guo H: Activation of hedgehog signaling and its association with cisplatin resistance in ovarian epithelial tumors. Oncol Lett 15: 5569-5576, 2018.

12. Steg AD, Burke MR, Amm HM, Katre AA, Dobbin ZC, Jeong DH and Landen CN: Proteasome inhibition reverses hedgehog inhibitor and taxane resistance in ovarian cancer. Oncotarget 5: 7065-7080, 2014.

13. Steg AD, Bevis KS, Katre AA,Ziebarth A, Dobbin ZC, Alvarez RD, Zhang K, Conner M and Landen CN: Stem cell pathways contribute to clinical chemoresistance in ovarian cancer. Clin Cancer Res 18: 869-881, 2012.

14. Yu SS and Cirillo N: The molecular markers of cancer stem cells in head and neck tumors. J Cell Physiol 235: 65-73, 2020.

15. Cao J, Zhao M, Liu J, Zhang X, Pei Y, Wang J, Yang X, Shen B and Zhang J: RACK1 promotes self-renewal and chemoresistance of cancer stem cells in human hepatocellular carcinoma through stabilizing nanog. Theranostics 9: 811-828, 2019.

16. Kakiuchi S, Minami Y, Miyata Y, Mizutani Y, Goto H, Kawamoto S, Yakushijin K, Kurata K, Matsuoka H and Minami H: NANOG expression as a responsive biomarker during treatment with hedgehog signal inhibitor in acute myeloid leukemia. Int J Mol Sci 18: 486, 2017.

17. Servo SF, Scully RE and Subin LH: Histologic typing of ovarian tumors. WHO Geneva, pp42-45, 1973.

18. Pecorelli S: Revised FIGO staging for carcinoma of the vulva, cervix, and endometrium. Int J Gynaecol Obstet 105: 103-104, 2009.

19. Remmele W and Stegner HE: Recommendation for uniform definition of an immunoreactive score (IRS) for immunohistochemical estrogen receptor detection (ER-ICA) in breast cancer tissue. Pathologe 8: 138-140, 1987 (In German).

20. Livak KJ and Schmittgen TD: Analysis of relative gene expression data using real-time quantitative PCR and the 2(-Delta Delta C(T)) method. Methods 25: 402-408, 2001.

21. Kubo M, Nakamura M, Tasaki A, Yamanaka N, Nakashima H, Nomura M, Kuroki S and Katano M: Hedgehog signaling pathway is a new therapeutic target for patients with breast cancer. Cancer Res 64: 6071-6074, 2004.

22. Feng YZ, Shiozawa T, Miyamoto T, Kashima H, Kurai M, Suzuki A, Ying-Song J and Konishi I: Overexpression of hedgehog signaling molecules and its involvement in the proliferation of endometrial carcinoma cells. Clin Cancer Res 13: 1389-1398, 2007.

23. Ozretić P, Trnski D, Musani V, Maurac I, Kalafatić D, Orešković S, Levanat S and Sabol M: Non-canonical hedgehog signaling activation in ovarian borderline tumors and ovarian carcinomas. Int J Oncol 51: 1869-1877, 2017.

24. Rokkam P, Gugalavath S, Gift Kumar DK, Vempati RK and Malla RR: Prognostic role of hedgehog GLI1 signaling pathway in aggressive and metastatic breast cancers. Curr Drug Metab 21: 33-43, 2020.

25. Wang C, Cheng L, Song S, Wu S and Sun G: Gli1 interacts with YAP1 to promote tumorigenesis in esophageal squamous cell carcinoma. J Cell Physiol 235: 8224-8235, 2020.

26. Ciucci A, De Stefano I, Vellone VG, Lisi L, Bottoni C, Scambia G, Zannoni GF and Gallo D: Expression of the glioma-associated oncogene homolog 1 (gli1) in advanced serous ovarian cancer is associated with unfavorable overall survival. PLoS One 8: e60145, 2013.

27. Schreiber L, Raanan C and Amsterdam A: CD24 and Nanog identify stem cells signature of ovarian epithelium and cysts that may develop to ovarian cancer. Acta Histochem 116: 399-406, 2014.

28. Sabol M, Trnski D, Uzarevic Z, Ozretic P, Musani V, Rafaj M, Cindric $M$ and Levanat S: Combination of cyclopamine and tamoxifen promotes survival and migration of mef-7 breast cancer cells-interaction of hedgehog-gli and estrogen receptor signaling pathways. PLoS One 9: e114510, 2014.

29. Ma Y, Yu W,Shrivastava A,AlemiF,Lankachandra K, Srivastava RK and Shankar S: Sanguinarine inhibits pancreatic cancer stem cell characteristics by inducing oxidative stress and suppressing sonic hedgehog-Gli-Nanog pathway. Carcinogenesis 38: 1047-1056, 2017.

This work is licensed under a Creative Commons Attribution-NonCommercial-NoDerivatives 4.0 International (CC BY-NC-ND 4.0) License. 